Article

\title{
Changes in Volatile and Non-Volatile Flavor Chemicals of "Valencia" Orange Juice over the Harvest Seasons
}

\author{
Jinhe Bai *, Elizabeth A. Baldwin, Greg McCollum, Anne Plotto, John A. Manthey, \\ Wilbur W. Widmer, Gary Luzio and Randall Cameron
}

Received: 25 November 2015; Accepted: 23 December 2015; Published: 4 January 2016

Academic Editor: Christopher J. Smith

USDA, ARS, U.S. Horticultural Research Laboratory, 2001 S. Rock Rd, Fort Pierce, FL 34945, USA; liz.baldwin@ars.usda.gov (E.A.B.); greg.mccollum@ars.usda.gov (G.M.); anne.plotto@ars.usda.gov (A.P.); john.manthey@ars.usda.gov (J.A.M.); wwidmer@gmail.com (W.W.W.); gary.luzio@ars.usda.gov (G.L.);

Randall.cameron@ars.usda.gov (R.C.)

* Correspondence: jinhe.bai@ars.usda.gov; Tel: +1-772-462-5880; Fax: +1-772-462-5986

\begin{abstract}
Florida "Valencia" oranges have a wide harvest window, covering four months after first reaching the commercial maturity. However, the influence of harvest time on juice flavor chemicals is not well documented, with the exception of sugars and acids. Therefore, we investigated the major flavor chemicals, volatile (aroma), non-volatile (taste) and mouth feel attributes, in the two harvest seasons (March to June in 2007 and February to May in 2012). Bitter limonoid compounds, limonin and nomilin, decreased gradually. Out of a total of 94 volatiles, 32 increased, 47 peaked mid to late season, and 15 decreased. Juice insoluble solids and pectin content increased over the season; however, pectin methylesterase activity remained unchanged. Fruit harvested in the earlier months had lower flavor quality. Juice from later harvests had a higher sugar/acid ratio with less bitterness, while, many important aroma compounds occurred at the highest concentrations in the middle to late season, but occurred at lower concentrations at the end of the season. The results provide information to the orange juice processing industry for selection of optimal harvest time and for setting of precise blending strategy.
\end{abstract}

Keywords: Citrus sinensis; maturity; orange juice; volatile; aroma; flavor; bitterness; limonoid

\section{Introduction}

"Valencia" is the predominant orange variety grown in Florida and is mainly used for juice. This variety is favored by the juice industry for the rich orange color and flavor [1]. The harvest season for "Valencia" oranges occurs typically from February to May or March to June, depending on the strain, year and location [2]. Florida maturity indices for oranges harvested between November 16 to July 31 are: soluble solids content (SSC, $\approx{ }^{\circ}$ Brix) $>8.5 \%$, titratable acidity (TA or acid) $>0.4 \%$, $\mathrm{SSC} / \mathrm{TA}$ ratio $>10.25$, and juice content $>\sim 45 \mathrm{~mL} / 100 \mathrm{~g}$ ( $4.5 \mathrm{gal}$ per 1.6 bushel box) [3]. There is a gradual decrease in acid by decomposition of citric acid, the principle organic acid of citrus juice, a slight increase in SSC and a consistent increase of SSC/TA ratio over the harvest season [4].

The major chemicals contributing to bitterness in orange juice (OJ) are the limonoids, limonin and nomilin. It has been noticed previously that limonin content decreased during the harvest season [5,6]. However, very little attention has been given to nomilin. Citrus greening, also known as Huanglongbing (HLB), has spread throughout the major citrus-producing regions in Florida and many other countries, and has largely accentuated OJ bitterness due to higher concentrations of limonin and nomilin in HLB-affected fruit $[7,8]$. This is particularly evident in "Hamlin" oranges which already 
have higher limonin and nomilin concentrations in healthy and HLB-affected fruit than in "Valencia" oranges [7]. Thus, since the arrival of HLB disease, bitter limonoids have become important to OJ flavor quality research.

Orange flavor is comprised of sugars, acids, limonoids, and a complex mixture of volatile compounds, of which some 200 have been identified [9]. Of those, only 20-40 are generally recognized as important aroma contributors to OJ, including esters, aldehydes, monoterpenes, sesquiterpenes, alcohols, ketones, and hydrocarbons [10-13]. Over the last half century, much effort has been focused on varietal selections, pre- and postharvest treatments, processing methods (such as extractor and finisher settings) and thermal pasteurization or concentration. Yet, little work has been published on influence of harvest maturity.

Among other factors that contribute to the quality of orange juice, the "cloud" is comprised of pectin and pulp particulates and provides some viscosity to the juice. The cloud can be destabilized or precipitated due to the action of the enzyme pectin methylesterase (PME) if this enzyme is not inactivated by heat [14]. The cloud also significantly contributes to flavor by binding hydrophobic molecules, such as volatile terpenes $[15,16]$.

Therefore, the goal of this study was to evaluate the overall flavor quality-related chemicals of "Valencia" fruit and juice-volatile aromas, non-volatile tastes, and mouth feel attributes, over the four-month commercial harvest seasons, in order to provide information to the OJ juice processing industry for selection of optimal harvest time and for setting of precise blending strategy.

\section{Experimental Section}

\subsection{Fruit and Juice Preparation}

In the 2007 experiment, fruit were harvested from five trees in a South Florida commercial grove on March 19, April 13, May 15, and June 29. At each harvest, 30 fruit were picked from each replicate tree. After measuring peel color, the fruit were sanitized with $200 \mathrm{mg} \cdot \mathrm{L}^{-1} \mathrm{NaOCl}$ for $30 \mathrm{~s}$, and gently hand juiced using a Sunkist J1 Commercial Citrus Orange Juicer (Sherman Oaks, CA, USA). Halved fruit were pressed onto the automatic self-reversing reamer, and seeds and segment membranes were screened by a strainer. The juice was lightly pasteurized $\left(71^{\circ} \mathrm{C}\right.$ for $15 \mathrm{~s}$ in a water bath) and frozen at $-20{ }^{\circ} \mathrm{C}$ until analyzed.

The 2012 experiment was similar to 2007 experiment except for the following changes: the orange grove was in the coastal Florida Indian River area, four trees were used and 20 fruit were picked from each replicate tree at each harvest. The harvest dates were 22 February, 21 March, 18 April, and 12 May. Fruit were cleaned with JBT Fruit Cleaner 395, and juiced using a fresh juicer (JBT Fresh'n Squeeze ${ }^{\circledR}$ Point-of-Sale Juicer, JBT FoodTech Corporation, Lakeland, FL, USA). Unfortunately, citrus greening or Huanglongbing (HLB) disease, associated with Liberibacter asiaticus (CLas), had spread throughout the major citrus producing regions in Florida by 2010 [17], and the diseased fruit were shown to be associated with off-flavor and other negative quality defects $[18,19]$. Therefore, to eliminate this potentially complicating factor, the trees or fruit juice was tested for the disease before sampling. Fruit for the 2007 juice samples were harvested from trees that were CLas free by leaf analysis using the $\mathrm{Li}$ et al. [20] real-time quantitative polymerase chain reaction (qPCR) method. The qPCR method of Bai et al. [21] as modified by Zhao et al. [22], was used to measure CLas in the juice and confirm that the juice samples for the 2012 harvest were disease free.

\subsection{General Fruit and Juice Features}

Fruit weight was measured individually and juice was pooled for each replicate and quantified for juice content (mL 100. $\mathrm{g}^{-1}$ of fruit) calculation. Juice color was measured with a Macbeth Color-Eye 3100 spectrophotometer (Kollmorgen Instruments Corp., Newburgh, NY, USA) and expressed as color number. Insoluble solids were determined by measuring dry weight residues of pellets obtained from centrifugations of juice. Briefly, juice samples were centrifuged at $27,000 \times \mathrm{g}$ for $30 \mathrm{~min}$. Supernatants 
were discarded and pellets were carefully re-suspended with deionized water (equivalent amount as in original juice) and centrifuged again. The final pellets, collected after centrifugation, were vacuum dried at $55{ }^{\circ} \mathrm{C}$. The ratio of dry weight to original juice weight represented the insoluble solids content [23].

Peel oil content was analyzed by a bromate titration method [24]. In brief, the juice sample $(25 \mathrm{~mL})$ and 2-propanol $(25 \mathrm{~mL})$ with a few boiling stones were distilled until the solvent ceased to reflux. After adding $10 \mathrm{~mL}$ of $4 \mathrm{~N} \mathrm{HCl}$ with a drop of $0.1 \%$ methyl red indicator, peel oil content was determined by titrating the distilled fraction with $0.025 \mathrm{~N}$ bromide-bromate solution until the color disappeared.

\subsection{Sugar and Acid Analyses}

Juice samples, $35 \mathrm{~mL}$, were centrifuged at $10,000 \times \mathrm{g}$ for $15 \mathrm{~min}$, and supernatants were used for SSC, TA and individual sugar and acid analysis. SSC was determined by using a refractometer (Atago RX-5000 cx, Tokyo, Japan). TA was determined by titrating juice supernatant to $\mathrm{pH} 8.1$ with $0.1 \mathrm{~N} \mathrm{NaOH}$ using an autotitrator (Metler Toledo DL50, Daigger \& Company, Vernon Hills, IL, USA) and the content was calculated as citric acid on juice weight basis. Individual sugars (sucrose, glucose and fructose) were measured by HPLC [23] using a Water Sugar Pak column and refractive index detector (Perkin Elmer, Norwalk, CT, USA) and acids (citrate and malate) by HPLC equipped with an Altech OA 1000 Prevail organic acid column (Altech Corp., Flemington, NJ, USA) and a Spectra System UV 6000 LP detector (Shimadzu, Kyoto, Japan) according to Baldwin et al. [23].

\subsection{Limonoid Analysis}

Different extraction methods were used in 2007 and 2012. In 2007, $150 \mathrm{~mL}$ of juice samples were centrifuged at $10,000 \times \mathrm{g}$ for $15 \mathrm{~min}$. Supernatant $(100 \mathrm{~mL})$ were extracted 3 times with equal volumes of methylene chloride. Combined extracts were rotovaporated to dryness and the residues redissolved in $12 \mathrm{~mL}$ acetone. The solutions were filtered through a $0.45 \mu \mathrm{m}$ PTFE filter (Siemens, Shrewbury, MA, USA), then taken to dryness with a Savant centrifugal evaporator (Milford, MA, USA). The residues were redissolved in acetone $(1 \mathrm{~mL})$ containing $4.35 \mu \mathrm{g}$ hesperetin as an internal standard prior to analysis. In 2012, $2 \mathrm{~mL}$ of juice sample was added to $10 \mathrm{~mL}$ of methanol in a Teflon gasket screw-top test tube and shaken for $18 \mathrm{~h}$ with an orbital shaker (VSOS-4P, Pro Scientific, Oxford, UK) at $120 \mathrm{rpm}$ at $25^{\circ} \mathrm{C}$. The mixtures were centrifuged at $10,000 \times \mathrm{g}$ for $15 \mathrm{~min}$. The total volume of supernatant was adjusted to $12 \mathrm{~mL}$ by methanol. Then $1 \mathrm{~mL}$ butanol was added, and the sample was taken to dryness using a Savant centrifugal evaporator. Methanol $(2 \mathrm{~mL})$ was added, and each sample was vortexed for $2 \mathrm{~min}$. Samples were then passed through a $0.45 \mu \mathrm{m}$ PTFE filter. The filter was washed with an additional $1.5 \mathrm{~mL}$ methanol. After adding $200 \mu \mathrm{L}$ of $0.13 \mathrm{mg} \cdot \mathrm{mL}^{-1}$ mangiferin (internal standard), the total volume was adjusted to $4 \mathrm{~mL}$ prior to analysis [25]. High-performance liquid chromatography-mass spectrometry (HPLC-MS) was used to separate and determine limonoid compounds described previously [26], and the column was Atlantis dC18 $(2.0 \times 100 \mathrm{~mm}$, Waters, Medford, MA, USA). The main fragment ions, $471 \mathrm{~m} / \mathrm{z}$ for limonin, and $515 \mathrm{~m} / \mathrm{z}$ for nomilin were used for their quantification. Standards for identification were obtained from Hasegawa and coworkers $[27,28]$.

\subsection{Volatile Analysis}

Juice samples in glass vials were crimp capped with Teflon/silicone septa. After incubation at $40{ }^{\circ} \mathrm{C}$, direct-headspace (DHS) gas samples were analyzed by a gas chromatograph for the 2007 harvest [23], and a headspace-solid phase microextraction (HS-SPME) and GC-MS method was used for analysis of 2012 samples [29].

Standards were obtained from the following sources: acetaldehyde, hexanal, (Z)-3-hexenal, octanal, nonanal, decanal, (E,E)-2,4-decadienal, citral, $\beta$-sinensal, ethanol, hexanol, linalool, D-limonene, $\alpha$-pinene, $\beta$-myrcene, $\gamma$-terpinene, nootkatone, ethyl butanoate, ethyl acetate, methyl butanoate, ethyl 2-methylbutanoate, and ethyl 3-hydroxyhexanoate were purchased from 
Sigma-Aldrich (Milwaukee, WI, USA), valencene was from Bedoukian (Danbury, CT, USA), and $\alpha$-terpineol from Advanced Biotech (Totowa, NJ, USA). Quantification for each component was conducted by using a peak size $v$ s. concentration curve built by serially diluted five point standard solutions [29]. Briefly, a standard compound was dissolved in pure methanol and the mixture was then introduced into a sugar equivalent deodorized orange juice (diluted "pumpout" concentrate) [11]. The range of concentrations in the standard curve for each compound covers the concentrations found in the samples. Other volatiles than listed here were not identified by comparing with the authentic chemical standards, but by comparing with library entries in NIST/EPA/NIH Mass Spectral Library 2011, as well as by comparing with published RIs [29].

\subsection{Pectin and PME}

Total pectin content was measured as galacturonic acid, determined using a microplate reader as described in Baldwin et al. [23]. Briefly, pectin was extracted from juice samples by adjusting to $\mathrm{pH} 2.4$ and heating in a closed vessel reactor with microwave irradiation for $5 \mathrm{~min}$. at $110{ }^{\circ} \mathrm{C}$. After precipitation by using isopropyl alcohol, the extracts were hydrolyzed by pectinase (Pectinex Ultra SP-L, P-2611, Sigma-Aldrich, St. Louis, MO, USA) at $\mathrm{pH} 5$ and $37^{\circ} \mathrm{C}$ for $24 \mathrm{~h}$. GA was determined by using anion exchange chromatography with a CarboPac PA1 column (Dionex Corp., Sunnyvale, CA, USA) and gradient elution using 0.0 to $0.5 \mathrm{M}$ ammonium formate (Fluka \#09735, Sigma-Aldrich, St. Louis, MO, USA) in water as mobile phase. For PME, $30 \mathrm{~mL}$ juice per sample was homogenized using a Brinkmann PT 10/35 homogenizer (Westbury, NY, USA) at speed 4 for $45 \mathrm{~s}$. PME activity was determined titrimetrically with $0.5 \%$ citrus pectin [23].

\subsection{Statistical Analysis}

Analysis of variance (ANOVA) for each attribute/compound was conducted using the ANOVA procedure in SAS (Version 9.3; SAS Institute, Gary, NC, USA). Mean separation was determined by Tukey's test at the $5 \%$ level. For multivariate statistical analyses, principal component analysis (PCA) and cluster analysis were performed using JMP (SAS Institute) to test the separation among harvest times based on the physical, chemical and biological measurements taken for this study. Heatmaps were generated based the average values by using Microsoft Excel 2013.

\section{Results and Discussion}

\subsection{General Fruit and Juice Features}

Average fruit weight increased by $\sim 3 \%$ per month from February/March to April/May, and then decreased by $\sim 4 \%$ in the last month in both 2007 and 2012 (Table 1), an occurrence associated with dehydration of the peel and browning of the fruit surface in the last month. Trends of peel oil content in the juice were similar to the fruit weight, increasing until April 2012, and then significantly decreasing in the last month, as much as $30 \%$ (Table 1). The maximum USDA designated oil content of "Grade A" $\mathrm{OJ}$ is $0.035 \%$ [30], while $0.01 \%-0.025 \%$ is preferred in most OJ [1]. Excessive peel oil in the OJ tends to be bitter or burning in taste character [31]. In this research, peel oil content in all juices were in the Grade A range with April juice having the highest content (Table 1). However, oil content in all the juice samples would have been much lower if the industrial juicer with the "Premium Setting" had been used, which is generally used to reduce peel oil content for "Valencia" fruit which have high levels of peel oil $[1,23]$. The increase in peel oil content before April 2012 may have been related to expanding oil glands during the development of peel tissues, and the decrease after April may have been due to the collapse of oil glands along with the dehydration of the peel [32]. Growth or regrowth of fruit and peel directly correlates to the enlargement of oil glands [31,33], and juice oils are overwhelmingly from these oil gland [12]. During senescence or under the stress of dehydration, cavities develop in oil glands of Citrus species, resulting in decreases of extractable peel oil yields [32]. The juice content to fruit weight decreased very slowly until mid-late season, and then substantially 
declined in the last month in both years (Table 1). The opposite trend was observed in insoluble solids content, which was unchanged until April 2012 and then sharply increased (Table 1). After reaching commercial harvest maturity, the fruit weight increased slowly in the early season, but in the later season the fruit underwent water loss from the peel, leading to reduced fruit weight and juice content, decreased turgor pressure in peel and collapsed oil glands. Thus, some of the peel oil could not be extracted, and with the decreased water content, the relative amount of insoluble solids naturally increased. Juice color number was high in the early season and decreased after mid-season (Table 1). Juice color is a primary quality attribute for orange juice. A USDA score of $36-40$ is considered to be grade A, and 32-35 constitutes grade B for most citrus products [1]. A higher color number reflects deeper colored juices. Carotenoid pigments are responsible for orange juice color. Tropical climates generally grow fruit that produce lighter color juices [1].

Table 1. Changes of the basic fruit/juice properties, and non-volatile and mouth feel related attributes including fruit size, peel oil, insoluble solids, pectin, activity of pectin methylesterase (PME), juice color number, juice content, titratable acids (TA), citric acid, malic acid, soluble solids content (SSC), sucrose, glucose, fructose, SSC/TA ratio, limonin and nomilin in "Valencia" orange fruit/juice extracted from fruit harvested in March to June $2007(n=5)$ and February to May, $2012(n=4)$.

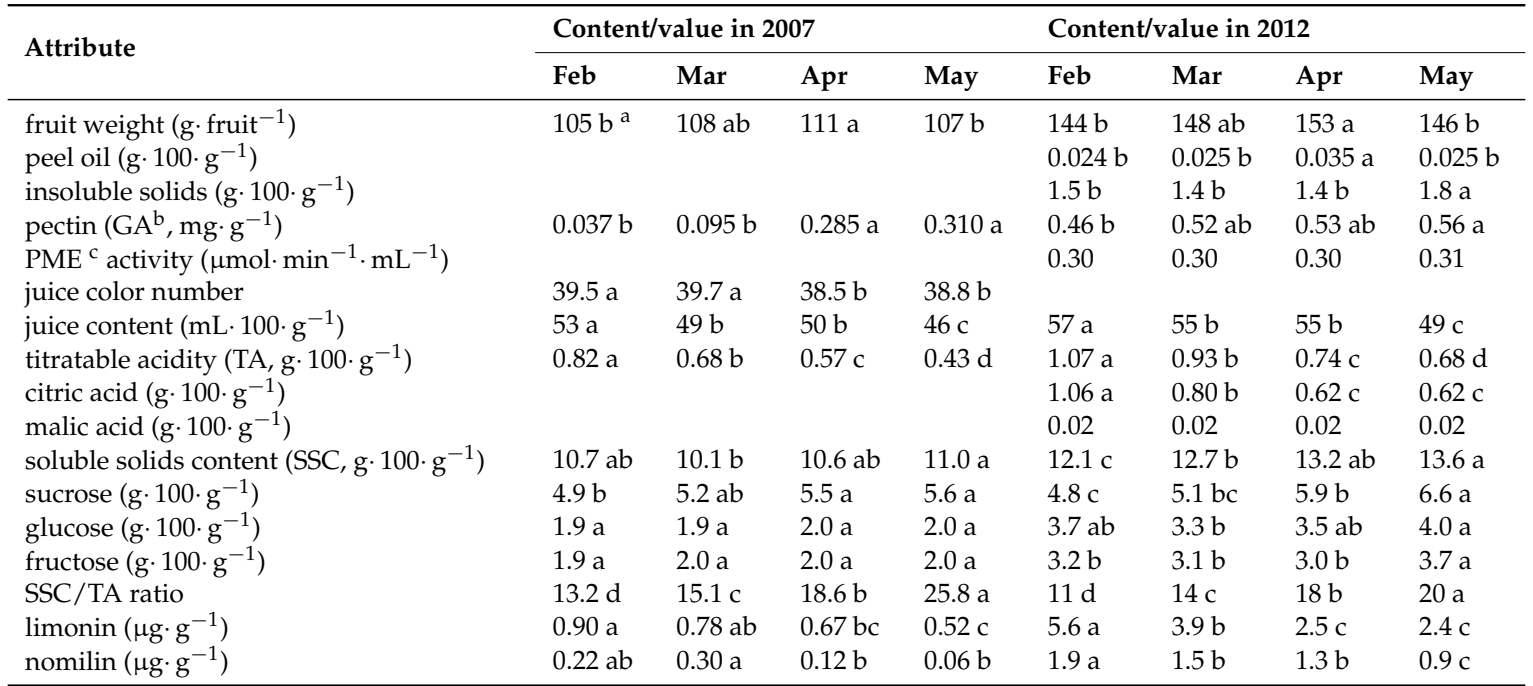

a Values that are not followed by the same letter in the same row show significant difference at the 0.05 level using Tukey's test; ${ }^{\text {b }}$ GA: galacturonic acid; ${ }^{c}$ PME: pectin methylesterase.

\subsection{Sugars and Acids}

SSC of the juice in the 2007 harvest season did not follow a "gradual increase" pattern [3] because of the high value in February, which might be caused by nonuniform sampling. decreased very slightly then increased over the 2007 harvest season from April to June (Table 1) and was unusually low. It climbed steadily in 2012 to over 16\% from February to May more in line with expectations (Table 1). Meanwhile, TA content decreased consistently over both harvest seasons as expected. Consequently, SSC/TA ratio increased steadily in both seasons to over 25 in June of 2007 and 20 in May 2012 (Table 1). All juices passed Florida juice standard (SSC/TA > 10.25), [3] however, high quality juice has a SSC/TA ratio between 12.5 and 19.5 [34]. The early harvested high acid fruit for both years had a SSC/TA ratio of around 11, out of the best quality range (Table 1). The last harvest in June of 2007 was too high (over 25, Table 1) to be in the optimal quality range due to an unpleasant overripe and insipid flavor that occurs when the SSC/TA ratio exceeds 20 [35,36]. Changes in TA and SSC/TA ratio are derived from some increase in SSC, but predominantly from a decrease in TA due to the decrease of citric acid, the dominant acid in citrus fruit. In mature orange juice sacs, both aconitase and citrate 
lyase activities were absent [37]. thus, decreasing the synthesis of oxaloacetate, the precursor of citrate, during maturation [38], which may play a major role in the acid decline over the season.

Individual sugars (sucrose, glucose and fructose) generally increased over the harvest seasons, but the significant differences only exhibited between March vs. May and June in sucrose in 2007, between first three months $v s$. the last month in fructose in 2012, between March vs. May in glucose in 2012, and among the different months in sucrose in 2012 (Table 1).

\subsection{Limonoids}

The bitter limonoids, limonin and nomilin generally decreased over the harvest season in both years, although the levels in 2012 were substantially higher than that in 2007 (Table 1). The results in this experiment showed that the fruit harvested in February 2012 had highest limonin levels, $5.6 \mu \mathrm{g} \cdot \mathrm{mL}^{-1}$ (Table 1); it is close to the group threshold of $6 \mu \mathrm{g} \cdot \mathrm{mL}^{-1}$ reported by Guadagni et al. [39]. The limonin content decreased gradually throughout the season (Table 1). Robertson and Nisperos [40] reported that limonin levels decreased in citrus fruits with advancing maturity. Kimball [41] pointed out that dilution and degradation during ripening causes a reduction in limonin levels. Dea et al. [42] reported that limonin and nomilin were shown to act synergistically, and together had a lower threshold than either compound alone [42].

Even though bitterness is considered to negatively impact OJ [42], a certain degree of bitterness is expected, and when combined with other desirable attributes, such as caffeine in coffee and alcohol in wine, bitterness can be an acquired taste in juice [43,44].

\subsection{Pectin and PME Activity}

Pectin, together with hemicellulose, cellulose and other minor components $[45,46]$ make up the OJ cloud particles which contribute to the characteristic flavor, color and mouthfeel of the juice [11,25]. Galacturonic acid is the main component of pectin [47], thus total pectin was measured as galacturonic acid. Galacturonic acid content in juice increased from $0.037 \mathrm{mg} \cdot \mathrm{g}^{-1}$ in March to $0.31 \mathrm{mg} \cdot \mathrm{g}^{-1}$ in June in 2007, which is over an 8-fold increase. In 2012, pectin levels were generally consistent over the season, although there was an increase of about $20 \%$ from February to May, and juice from the later harvested fruit had wide variability (Table 1). The results are in contrast to Sinclair and Jolliffe [48] and Rouse et al. [49] who observed that in maturing oranges, total pectin and water-soluble pectic substances decreased in the peel and pulp, in both California and Florida "Valencia" fruit. However, Rouse and Moore [50] reported that pectin content in "Valencia" OJ increased in the 1973 season, but decreased in 1974. A possible reason for the increase of juice pectin is that when fruit were harvested later, a softening of albedo and membrane tissues may have occurred that can result in small amounts of these materials entering the juice during processing [50,51]. Because of the high pectin content in juice, the later harvested fruit can be problematic for potentially high cloud loss. PME is an enzyme that demethylates pectin in cell walls and can destabilize the cloud in OJ [23,52]. However, PME activity stayed stable over the season (Table 1).

\subsection{Volatiles}

In 2012, a total of 94 volatile compounds detected by the HS-SPME-GC-MS analysis are listed, where 32 compounds were detected in all samples, 31 in 50\%-<100\% of samples, and remaining 31 less than $50 \%$, in which, 6 compounds, mostly terpenes were only detected at one harvest time, generally in April (Figure 1). The compounds were divided into three groups (A-C) by increasing and decreasing concentration patterns during the season (Figure 1). Group A consisted of 32 compounds that generally increased or changed little in the early months and for which the highest level was found in May (Figure 1). The representative chemical classes in this group are ethyl and methyl aliphatic esters, short chain ( $\leqslant$ carbon 6) aldehydes, alcohols and ketones, and sesquiterpene hydrocarbons, such as the important and/or abundant OJ aroma contributors ethyl butanoate, ethyl 2-methylbutanoate and ethyl acetate, (Z)-3-hexenal, ethanol and hexanol, and valencene (Table 2). There were 7 sub-groups 
(A1-A7) in this group. Ten compounds in A1 continually increased, and another 10 compounds in $\mathrm{A} 2$ and $\mathrm{A} 3$ remained low for the first one or two months and then increased (Figure 1). The other 4 sub-groups (A4-A7) containing 12 compounds, all reached their highest levels in the last month, however, fluctuated in the early stages (Figure 1). The average detection frequency in this group was $68 \%$ in February, and continually increased to $72 \%, 82 \%$ and $91 \%$, in following months, which follow the same trend as for the average peak sizes, although there were 16 compounds that were detected in all stages in this group (Figure 1). It is generally recognized that the sesquiterpene hydrocarbons are derived from acetyl-CoA through the mevalonic acid (MVA) pathway in the cytosol [53,54]. Valencene, the dominant sesquiterpene hydrocarbon, occurs in both peel oil (from oil glands in the flavedo) and juice oil (from oil bodies in the juice sacs). Since the OJ essence oil contains a high level of valencene, juice oil is recognized as a major source [12].

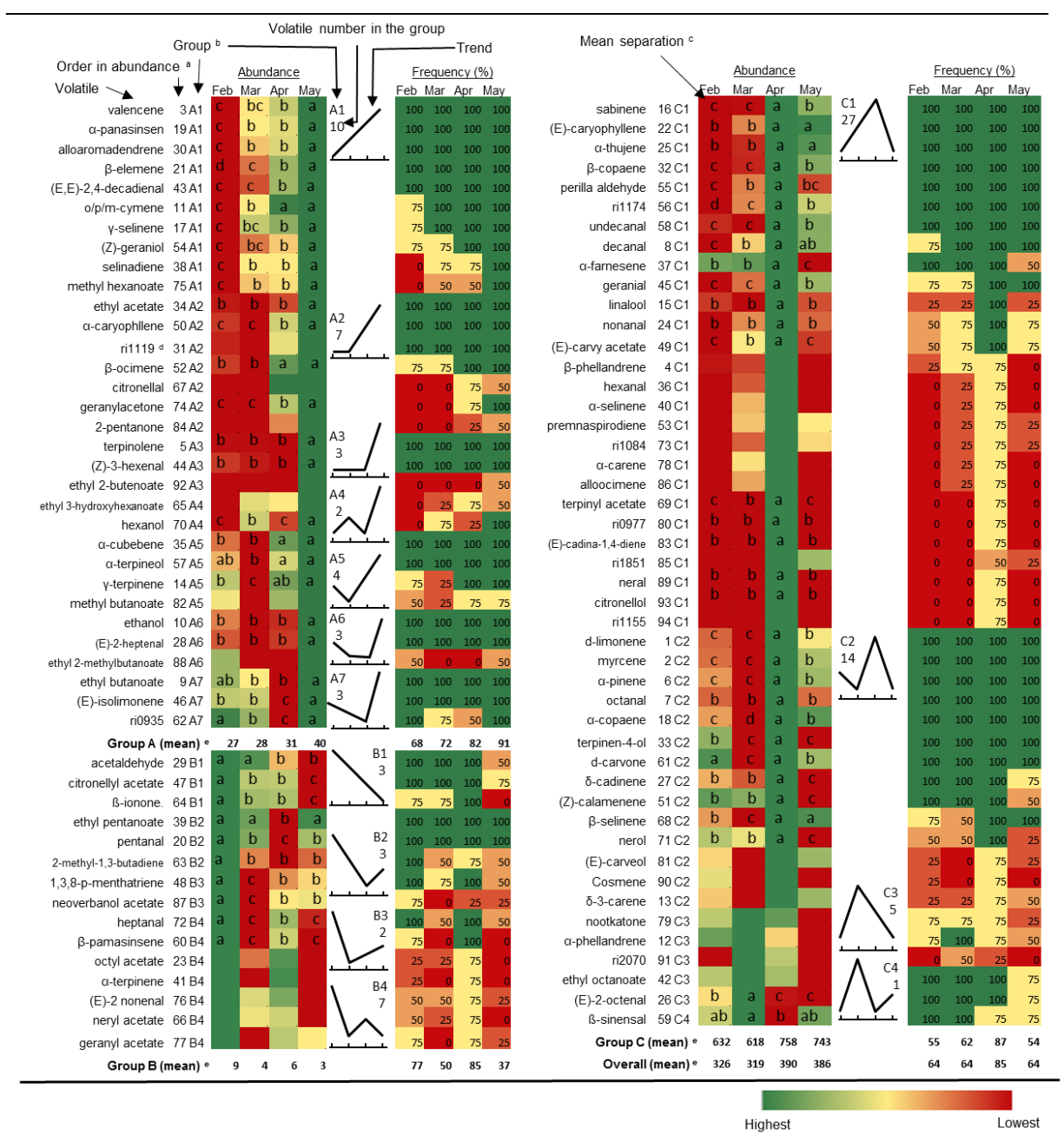

Figure 1. Changes in volatile abundance and frequency of detection in "Valencia" orange juice samples harvested from February to May $2012(n=4) .{ }^{\mathrm{a}}$ order in abundance listed by average peak size (total ion current) from high to low in total of 94 peaks; ${ }^{b}$ groups: A-increase; B-decrease; C-peak with sub-groups in numbers; ${ }^{c}$ the same letter within the same row (compound) represents no significant different at 0.05 level; ${ }^{d}$ unknown compound with the retention indices (ri + a 4 digital number); ${ }^{\text {e Average }}$ abundance ( $\times 10^{7}$ total ion current) and frequency of detection (\%).

Ethanol and ethyl moieties from esters are derived from the fermentation process, and the increased fermentation that occurs with progressed maturity is most likely the cause of enhanced production of those chemical classes $[55,56]$. The accumulation of methanol in ripe tomato fruit was 
likely the source of generated methyl esters with increased PME activity [57]. Beekwilder et al. [58] confirmed that the availability of alcohol substrates is an important parameter to consider when engineering volatile ester formation in plants. Carbon 5 and 6 aldehydes and alcohols are derived from polyunsaturated fatty acids, via the lipoxygenase (LOX) pathway [59], and the accumulation in the late stages of ripening could be accelerated by hydrolysis of membrane lipids during the maturity progresses $[60,61]$. For ethyl 2-methylbutanoate, which contains branch-chained acid moieties derived from isoleucine [62], the increased production with progressed maturity, may mostly be due to increased availability of ethanol, rather than the biosynthesis of the acid moieties [56].

Group B consisted of 15 components which were at highest level in February, and decreased thereafter (3 components in B1 sub-group) or fluctuated (12 components in B2-B4 sub-groups) in the later months (Figure 1). The average peak areas in this group were 9, 4, 6 and $3\left(\times 10^{6}\right)$, from February to May (Figure 1). The average detection frequency was $77 \%$ in February, and decreased to $50 \%$ and $37 \%$ in March and May, respectively (Figure 1). However, the value was $83 \%$ in April, higher than any other months (Figure 1). This group included many esters, and the representative chemicals were acetate esters, including four terpenic and one aliphatic acetate. It seems that the large increase in ethanol at later stages outcompeted the other alcohol moieties to be esterified [56]. Acetaldehyde increased in reduction capacity in the fermentation pathway. Beltrán, et al. [63] observed the accumulation of both ethanol and acetaldehyde in olive fruit during maturation, although ethanol showed a more rapid increase.

Group C consisted of 47 components, $50 \%$ of total volatile compounds detected in this research, which peaked in March or April (Figure 1). The representative chemical classes in this group included monoterpene hydrocarbons and straight-chain saturated aldehydes (C8-C10). Most of these compounds, 41 in total, peaked in April, which coincided with the change in peel oil content (Table 1 and Figure 1). The average detection frequency followed the same trend as for the change of concentration: 55\%,62\%, 87\% and 54\% in February to May (Figure 1). Monoterpene hydrocarbons are derived from pyruvic acid, and biosynthesized through the 2-C-methyl-D-erythritol-4-phosphate (MEP) pathway in plastids [64]. In orange juice, monoterpenes are predominantly from the peel oil and introduced into juice through processing $[9,12,23,25]$. Chemicals in this class comprise over $90 \%$ of total citrus volatiles and play a fundamental role in citrus aroma [12,29]. Many reports showed that the homologous straight-chain aldehydes, octanal, nonanal and decanal, are associated with peel oils [12]. Together with other aldehydes, this class of chemicals play a major role in orange flavor. Total aldehyde content has been used as one of the industry standards for high quality cold-pressed peel oil [65], although not all aldehydes contribute positive flavor to orange juice [12]. The decease of peel oil content, along with the majority of volatiles associated with peel oil after April coincided with fruit (especially peel) dehydration, perhaps was caused by the collapsing of oil glands [66].

Table 2 listed 23 important aroma contributors in orange juice $[10,11,67]$ and their changes during the 2007 and 2012 harvest seasons. In 2007, DHS sampling method was used and only 22 volatiles were detected, and of which 13 important compounds were listed in Table 2. Overall, D-limonene, myrcene, linalool, $\beta$-sinensal, acetaldehyde, hexanal, (Z)-3-hexenal, octanal, decanal, (E,E)-2,4-decadienal, ethyl butanoate, and ethyl 2-methyl butanoate were present at or above their odor threshold, i.e., the odor active value $(\mathrm{OAV})>1$ for at least one harvest (Table 2). It is important to note that the odor thresholds listed are based on an OJ matrix, and the values are much higher than those reported for water based thresholds [10,11]. 
Table 2. Change of 23 important comtributers to orange juice aroma quality in juices extracted from "Valencia" oranges harvested from March to June 2007 and Feburary to May 2012.

\begin{tabular}{|c|c|c|c|c|c|c|c|c|c|c|c|c|c|c|c|c|}
\hline \multirow{2}{*}{ Compound } & \multirow{2}{*}{ Oder Description a } & \multirow{2}{*}{$\begin{array}{l}\text { Threshold in } \\
\text { OJ Matrix } \\
\left(\text { ug. } \mathrm{mL}^{-1}\right)^{\mathrm{b}}\end{array}$} & \multicolumn{4}{|c|}{ Concentration $\left(\mu \mathrm{g} \cdot \mathrm{mL}^{-1}\right)$ by DHS in 2007} & \multicolumn{10}{|c|}{ Concentration $\left(\mu \mathrm{g} \cdot \mathrm{mL}^{-1}\right)$ by HS-SPME in 2012} \\
\hline & & & Group $^{c}$ & Mar & Apr & May & Jun & Group $^{c}$ & Feb & & Mar & & Apr & & May & \\
\hline D-limonene & Citrus, lemon, minty & 13.3 & $\mathrm{C} 1$ & $58 \mathrm{~b}^{\mathrm{d}}$ & $90 \mathrm{~b}$ & $336 \mathrm{a}$ & 302 a & $\mathrm{C} 2$ & 224 & c & 217 & c & 298 & a & 248 & $\mathrm{~b}$ \\
\hline myrcene & Mossy, musty, geranium & 0.5 & $\mathrm{C} 1$ & $0 \quad \mathrm{~b}$ & $0 \quad \mathrm{~b}$ & $2.64 \mathrm{a}$ & $2.53 \mathrm{a}$ & $\mathrm{C} 2$ & 0.86 & c & 0.78 & c & 1.42 & a & 1.15 & $\mathrm{~b}$ \\
\hline$\alpha$-pinene & Resin, pine tree, ethereal & 2.0 & $\mathrm{C} 1$ & $0.1 \mathrm{~b}$ & $0.15 \mathrm{~b}$ & $0.83 \mathrm{a}$ & $0.79 \mathrm{a}$ & $\mathrm{C} 2$ & 0.38 & c & 0.32 & c & 0.66 & $\mathrm{a}$ & 0.53 & $\mathrm{~b}$ \\
\hline$\gamma$-terpinene & Sweet, citrus & $2.1 \mathrm{e}$ & & & & & & A5 & 0.0038 & & 0.0010 & & 0.0049 & $9 \mathrm{ab}$ & 0.0060 & \\
\hline valencene & Lemon, floral & 10.5 & B2 & $2.71 \mathrm{a}$ & $2.59 \mathrm{a}$ & $2.46 \mathrm{a}$ & $2.49 \mathrm{a}$ & A1 & 2.1 & c & 2.5 & $\mathrm{bc}$ & 2.8 & $\mathrm{~b}$ & 3.3 & a \\
\hline linalool & Floral, fruity, sweet & 0.1 & $\mathrm{C} 1$ & $1.66 \mathrm{c}$ & $2.1 \mathrm{~b}$ & $3.15 \mathrm{a}$ & 2.9 a & $\mathrm{C} 1$ & 0.17 & $\mathrm{~b}$ & 0.12 & $\mathrm{~b}$ & 1.05 & a & 0.20 & $\mathrm{~b}$ \\
\hline$\alpha$-terpineol & Lemon, minty, piney & 9.1 & A7 & $0.94 \mathrm{a}$ & $0.8 \mathrm{~b}$ & $0.76 \mathrm{~b}$ & $0.99 \mathrm{a}$ & A5 & 0.15 & $a b$ & 0.14 & $\mathrm{~b}$ & 0.17 & $\mathrm{a}$ & 0.20 & $\mathrm{a}$ \\
\hline nootkatone & Grapefruit, green & 3.1 & & & & & & C3 & 0.080 & & 0.12 & & 0.11 & & 0.03 & \\
\hline geranial & Citrus, minty, green & 0.7 & & & & & & $\mathrm{C} 1$ & 0.031 & c & 0.022 & c & 0.042 & & 0.036 & $\mathrm{~b}$ \\
\hline neral & Citrus, lemon, minty & 0.7 & & & & & & $\mathrm{C} 1$ & $\operatorname{tr}$ & $\mathrm{b}$ & $\operatorname{tr}$ & $\mathrm{b}$ & 0.0033 & & $\operatorname{tr}$ & $\mathrm{b}$ \\
\hline$\beta$-sinensal & orange, fruity & $0.004^{\mathrm{f}}$ & & & & & & $\mathrm{C} 4$ & 0.0023 & & 0.0030 & & 0.0083 & & 0.0061 & $1 \mathrm{~b}$ \\
\hline acetaldehyde & Fresh, fruity, solvent & 0.3 & $\mathrm{C} 4$ & $4.9 \mathrm{a}$ & 8.1 a & $7.2 \mathrm{a}$ & $7.8 \mathrm{a}$ & B1 & 4.1 & a & 3.7 & a & 2.2 & $\mathrm{~b}$ & 1.6 & $\mathrm{~b}$ \\
\hline hexanal & Grassy, green, soapy & 0.09 & A5 & $0.04 \mathrm{~b}$ & $0.02 \mathrm{c}$ & $0.04 \mathrm{~b}$ & $0.07 \mathrm{a}$ & $\mathrm{C} 1$ & 0.000 & & 0.03 & & 0.27 & & 0.00 & \\
\hline (Z)-3-hexenal & Green, grassy & 0.02 & & & & & & A3 & 0.019 & $\mathrm{~b}$ & 0.017 & $\mathrm{~b}$ & 0.016 & $\mathrm{~b}$ & 0.047 & $\mathrm{a}$ \\
\hline octanal & Floral, citrus, green & 0.1 & $\mathrm{C} 1$ & $\mathrm{~b}$ & $0.04 \mathrm{~b}$ & $0.53 \mathrm{a}$ & $0.05 \mathrm{~b}$ & $\mathrm{C} 2$ & 0.12 & $\mathrm{~b}$ & 0.10 & $\mathrm{~b}$ & 0.21 & $\mathrm{a}$ & 0.12 & $\mathrm{~b}$ \\
\hline nonanal & Citrus, floral, soapy & 0.2 & & & & & & $\mathrm{C} 1$ & 0.004 & $\mathrm{~b}$ & 0.006 & $\mathrm{~b}$ & 0.017 & $\mathrm{a}$ & 0.006 & $\mathrm{~b}$ \\
\hline decanal & Citrus, fatty, green & 0.1 & $\mathrm{C} 1$ & $0.05 \mathrm{c}$ & $0.05 \mathrm{c}$ & $0.26 \mathrm{a}$ & $0.01 \mathrm{~b}$ & $\mathrm{C} 1$ & 0.143 & c & 0.180 & $\mathrm{~b}$ & 0.287 & $\mathrm{a}$ & 0.257 & $\mathrm{ab}$ \\
\hline$(\mathrm{E}, \mathrm{E})$-2,4-decadienal & Fatty, waxy, green & 0.004 & & & & & & A1 & 0.027 & $\mathrm{~b}$ & 0.033 & c & 0.061 & $\mathrm{~b}$ & 0.079 & a \\
\hline ethyl acetate & Fruity, solvent & 11.0 & B4 & 3.86 a & $3.27 \mathrm{~b}$ & $3.43 \mathrm{~b}$ & $3.02 \mathrm{c}$ & A2 & 0.24 & $\mathrm{~b}$ & 0.25 & $\mathrm{~b}$ & 0.26 & $\mathrm{~b}$ & 0.49 & $\mathrm{a}$ \\
\hline ethyl butanoate & Fruity, pineapple & 0.005 & $\mathrm{C} 3$ & $0.06 \mathrm{~b}$ & $0.86 \mathrm{a}$ & $0.09 \mathrm{a}$ & $0.08 \mathrm{a}$ & A7 & 0.90 & $a b$ & 0.89 & $\mathrm{~b}$ & 0.77 & $\mathrm{~b}$ & 1.21 & $\mathrm{a}$ \\
\hline methyl butanoate & Fruity, stawberry & 0.4 & $\mathrm{C} 1$ & $0.01 \mathrm{~b}$ & $0.02 \mathrm{ab}$ & $0.04 \mathrm{a}$ & $0.03 \mathrm{ab}$ & A5 & 0.014 & & 0.007 & & 0.019 & & 0.025 & \\
\hline ethyl 2-methylbutanoate & Fruity & 0.0002 & & & & & & A6 & 0.025 & & $\operatorname{tr}$ & & $\operatorname{tr}$ & & 0.038 & \\
\hline ethyl 3-hydroxyhexanoate & Citrus & 10.2 & & & & & & A4 & 0.325 & & 0.155 & & 0.183 & & 0.197 & \\
\hline
\end{tabular}

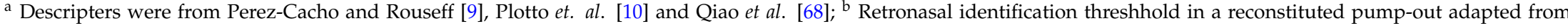
Plotto et al. [10,11] except described otherwise; ${ }^{c}$ Group: A: increased; B: decreased; C: peaked. See Figure 1 for details; ${ }^{\mathrm{d}}$ Values followed by different letters in the same compounds and same year (row) are significant different at $p=0.05$ using Tukey's test; $^{\mathrm{e}}$ Threshold in water [11]; ${ }^{\mathrm{f}}$ Threshold in water [69]. 
Cluster analysis (Figure 2) using all 94 volatile components showed that all samples discriminated by their harvest time, with February and March samples being more closely associated each other and April samples having the most distance from the other harvests (Figure 2).

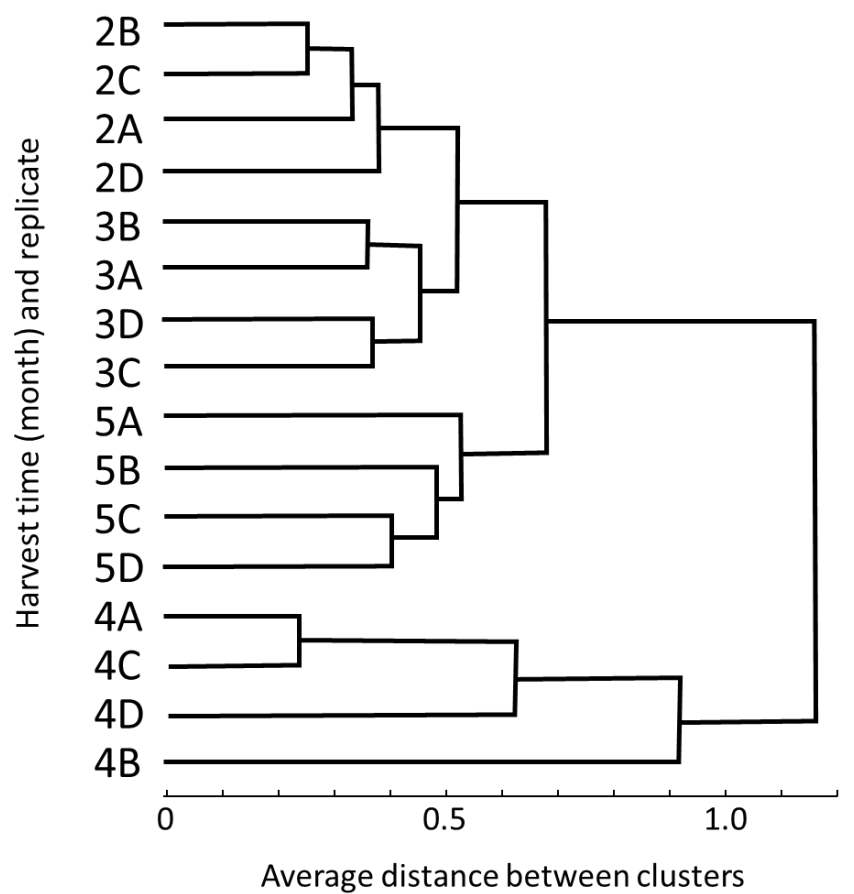

Figure 2. Cluster analysis of aroma quality of "Valencia" orange juice harvested from February to May 2012 based on 94 volatile compounds. "2"-“5" represent months ( 2 = February, 3 = March, 4 = April and 5 = May) and A-D represent replicates.

More than half of the important volatiles, 9 out of 13 compounds in 2007, and 12 out of 23 compounds in 2012 were in group C, and generally peaked in mid-late seasons (Table 2). The typical chemical classes were monoterpenes, straight-chain aliphatic and terpenic aldehydes (Table 2). The most abundant volatiles in OJ are monoterpenes, especially D-limonene, which counts for about $95 \%$ of total peel oil and is an important contributor to citrus and orange aroma [12,68]. Another two abundant and important monoterpene aroma contributors are $\alpha$-pinene and myrcene. The firmer makes a positive contribution to orange flavor and the latter can be a negative contributor [68,69], denoting pungency and bitterness at high concentration [70]. All aroma active terpenic and non-terpenic aldehydes determined in this research were in group C except acetaldehyde, (Z)-3-hexenal and (E,E)-2,4-decadienal. In the group $C$, neral and geranial are monoterpenic aldehydes, and possess a lemon, citrus-like odor, and $\beta$-sinensal, a sesquiterpenic aldehyde, possesses a sweet aroma (Table 2). $\alpha$-Sinensal was not detectable in this experiment as the $\alpha$-isomer concentration is only half that of the $\beta$-sinensal in OJ [71]. The odor properties of octanal, decanal and nonanal are slightly different from each other. All of them are pungent, with octanal and nonanal producing a citrus-like odor and decanal eliciting a cilantro note [72]. Hexanal contributes a green and grassy aroma, but may not be an important flavor attributor to OJ [9]. Linalool is generally from peel oil and a major odorant in commercial juice, contributing a sweet floral odor [73]. Nootkatone is a sesquiterpene ketone and characterized as having a grapefruit flavor [12]. However, it may contribute a citrus-like background to orange juice [9]. In comparison to group C, the increase in concentration of group A chemicals did not stop after April, and reached a maximum in May (Figure 1). Firstly, the five ethyl esters all increased continually in 2012, but reached peak or flatted out before the last harvest in 2007. Ethyl butanoate, with a high concentration and low threshold, is one of the single most important aromas to OJ with a fruity top-note [9]. Valencene, a sesquiterpene hydrocarbon, has little direct effect on OJ flavor 
due to its high odor threshold $[12,68]$, but is very abundant, and like limonene can affect headspace partitioning and, thus, the perception of other volatiles [10]. In hand-squeezed fresh OJ, with low peel oil content, valencence played an important role in contributing a citrus-like aroma note [74]. $\alpha$-Terpineol, formed from D-limonene and linalool, may contribute either a positive (floral, lilac-like) or negative (turpentine-like, musty, pungent) role in fruits, however, it is often used as an indicator for canned juice that has been stored too long [75]. Reasons for the continual increase of this compound together with $\gamma$-terpinene, (Z)-3-hexenal and (E,E)-2, 4-decadienal are unknown. (Z)-3-Hexenal has a lower threshold than hexanal and contributes a green top-note to fresh OJ [9]. (E,E)-2,4-Decadienal in citrus oils is produced by oxidative breakdown of the long chain fatty acids present in the oils $[9,76]$, and provides a positive aroma contribution to orange juice [76]. $\gamma$-Terpinene contributes a sweet and citrus aroma [9]. There were two compounds, valencene and ethyl acetate in 2007, and one compound, acetaldehyde in 2012 in group B and decreased during the harvest season (Table 2). Acetaldehyde is considered important to orange flavor [12,36,77], and contributes a fresh fruity flavor [12]. As discussed earlier, both valencene and ethyl acetate have little aroma impact due to their high odor thresholds.

\subsection{Overall Flavor Quality}

To get a clear picture of the changes in flavor chemicals over the harvest season, PCA analysis were performed by using the major orange juice taste contributors for sweetness, sourness and bitterness (SSC, TA, SSC / TA, limonin and nomilin), as well as other components that can indirectly influence OJ flavor and mouthfeel (peel oil, pectin and insoluble solids) and the 23 important aroma volatile compounds listed in Table 2 for 2012 samples (Figure 3c,d). There were less aroma compounds and mouthfeel attributes detected in the 2007 samples, although similar PCA procedure was performed (Figure 3a,b). For the 2007 samples, the PCA components 1 and 2 (PC1 and PC2) explained $52.8 \%$ and $14.0 \%$ of the variation, respectively (Figure 3). The score plot (Figure 3a) shows a clear separation of early (March and April) and late (May and June) harvested samples by PC1, and the sub-clusters by PC2 (Figure 3a). The factor loadings plot (Figure 3b) shows that TA, limonin, nomilin, and valencene were associated with early harvested $\mathrm{OJ}$, although valencene played only a small role (Figure 3b). Late harvested, May and June 2007 fruit were associated with D-limonene, $\alpha$-pinene, myrcene, linalool and pectin. May fruits more related to octanal, decanal, ethyl butanoate and methyl butanoate, while June fruits more related to SSC, SSC/CA ratio, ethyl acetate, and hexanal (Figure 3b). Acetaldehyde and $\alpha$-terpineol played little role (Figure $3 b$ ).

The 2012 data exhibited similar patterns to the 2007 data (Figure 3). The PC1 and PC2 explained $44.1 \%$ and $21.8 \%$ of the variation, respectively (Figure $3 \mathrm{c}$ and $3 \mathrm{~d}$ ). The score plot (Figure $3 \mathrm{c}$ ) shows a clear separation of early (February and March) and late (April and May) harvested samples by PC1, and April and May samples by PC2 (Figure 3a). February and March samples were not separated clearly, although more samples in March were closer to the later harvested fruit by PC1 (Figure 3a). The factor loadings plot (Figure 3b) shows that TA, limonin, nomilin, ethyl butanoate, ethyl acetate, (Z)-3-hexenal, SSC, valencene, $\alpha$-terpineol, sinensal, $\alpha$-pinene, myrcene, octanal, nonanal, neral, and peel oil exhibited strong discrimination power, ethyl 3-hydroxyhexanoate, ethyl octanoate, methyl butanoate, hexanal, and nootkatone played only small roles in discriminating samples, and others were in between in contributing to the discrimination of samples. Small conflicts between the two years were seen in some volatile compounds, such as valencene and acetaldehyde, but they played little roles in the discrimination (Figure $3 b, d$ ). 
(a) PCA scores plot 2007

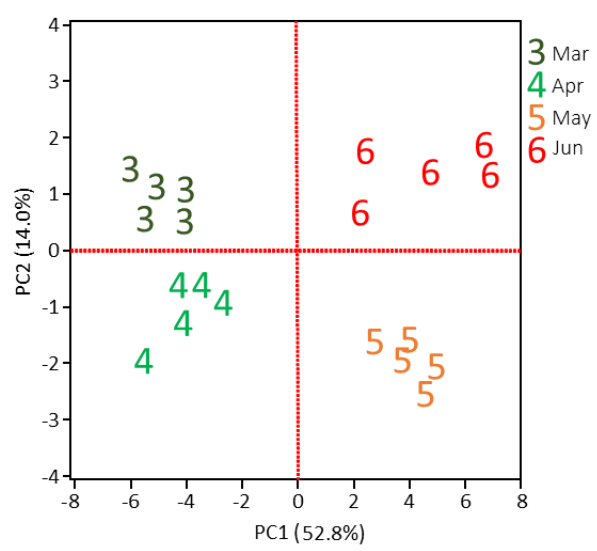

(c) PCA scores plot 2012

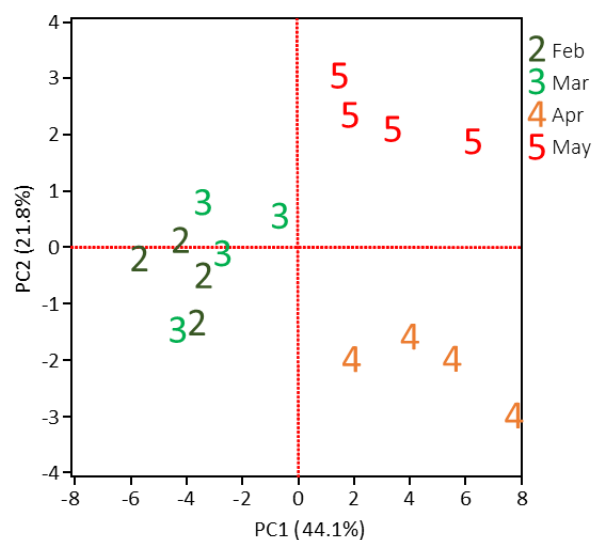

(b) PCA loading plot 2007

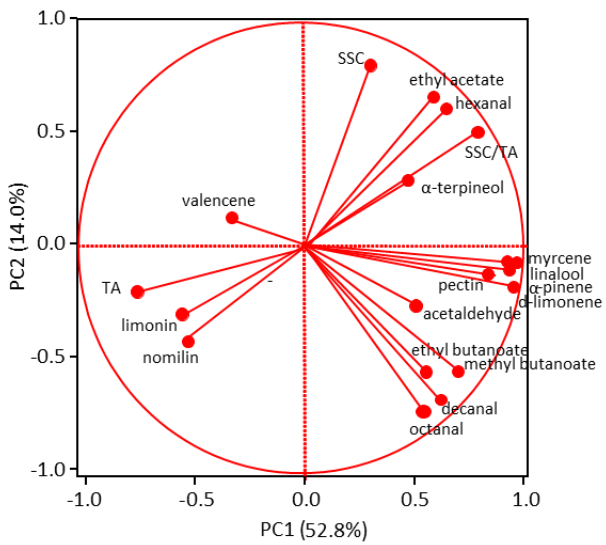

(d) PCA loading plot 2012

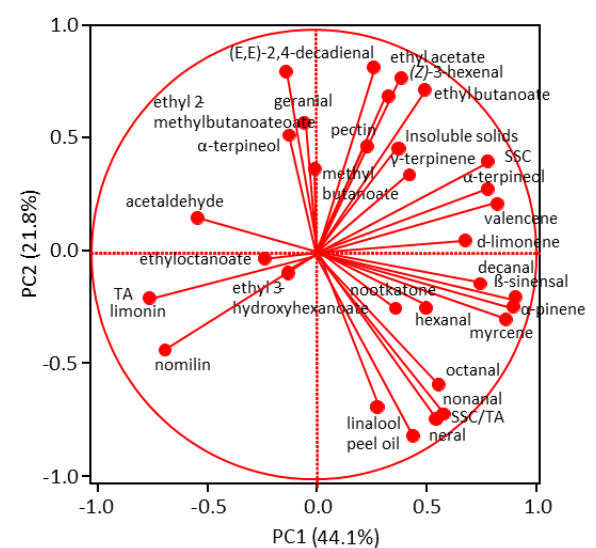

Figure 3. Principle component analysis (PCA) of important attributes of aroma, taste, and mouth feel components of Valencia' orange juice harvested over the 2007 and 2012 seasons. (a) and (b) PCA scores plot and loading plot in 2007, respectively. (c) and (d) PCA scores plot and loading plot in 2012, respectively. Component numbers for volatile, non-volatile and mouth feel attributes were 13, 5 and 1, respectively in 2007 and 23, 5, and 3, respectively in 2012.

There are many indications that aroma chemicals (volatiles), taste chemicals and the matrix interact physically and chemically and in terms of flavor perception [11,78]. Nonanal, octanal and decanal in all samples were found at subthreshold concentrations (Table 2), thus, their aromas should not be detectable individually, but may enhance each other in combination [78]. Similar effects have been found with ethyl esters, and monoterpenes in OJ $[9,12]$. Esters with fruity aroma often enhance fruit sweetness and suppress sourness [78]. Futhermore, the juice matrix in OJ influences complicates flavor perception. Brat, Rega, Alter, Reynes and Brillouet [15] and Radford, Kawashima, Friedel, Pope and Gianturco [16] showed that terpene hydrocarbons were associated with OJ pulp and ethyl butanoate and octanal were mainly in aqueous solution, indicating the influence of increased insoluble solids and pectin content on flavor perception later in the season due to changes in headspace partitioning of some compounds like terpene hydrocarbons (Figure 4). 


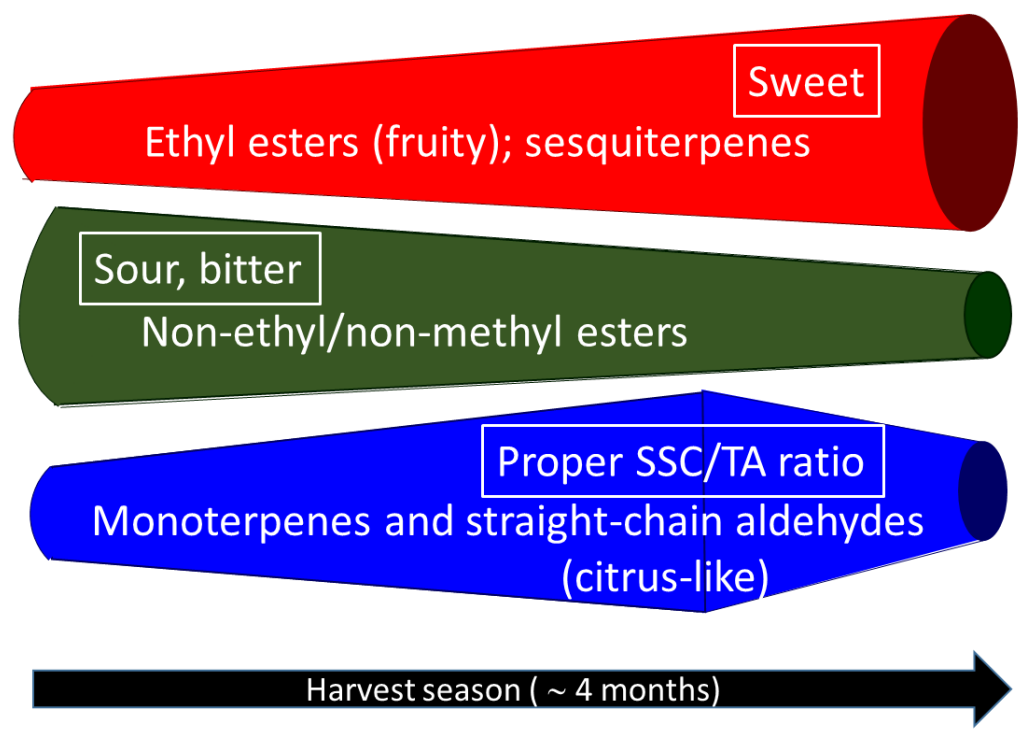

Figure 4. A schematic diagram to demonstrate the change patterns of different non-volatile (boxed) and volatile (non-boxed) flavor chemical compounds along with harvest time (from February/March to May/June) in "Valencia" orange juice. The width of the band indicates the relative abundance of each chemical class/attribute except for SSC/TA ratio which represents the optimal quality.

\section{Conclusions}

"Valencia" oranges harvested in the middle to late season (May 2007 and April 2012) are preferred for high quality juice with optimum SSC, TA, and SSC/TA ratio, and better volatile profiles. The early harvested fruit had high juice yield, but also had undesirable levels of bitter and sour compounds and lower levels of volatiles. After reaching optimal quality, monoterpene compounds, representing citrus-like aromas, decreased along with peel oil, although ethyl esters with the fruity top-note increased continually. With the SSC/TA ratio approaching 20 in later harvested samples, the juice quality falls out of the set commercial parameters for orange juice. In total, 94 volatiles were detected in the 2012 juice samples, and separated to 3 groups by the increase/decrease trends during the harvest season: 32 components in group A increased continually, including important and/or abundant $\mathrm{OJ}$ aroma contributors, such as ethyl butanoate, ethyl 2-methylbutanoate, ethyl acetate, (Z)-3-hexenal, ethanol, hexanol, and valencene; 15 components in group B decreased in general, including acetaldehyde and some acetate esters; rest of 47 components, as group $\mathrm{C}$, including D-limonene, myrcene, $\alpha$-pinene, octanal, nonanal, and sinensal, mostly peaked at April and some at March. The average detected peak number in April samples were 85, in comparison with 64 in February, March and May harvested samples.

\section{Disclaimer}

This article is a US Government work and is in the public domain in the USA. Mention of a trademark or proprietary product is for identification only and does not imply a guarantee or warranty of the product by the US Department of Agriculture. The US Department of Agriculture prohibits discrimination in all its programs and activities on the basis of race, color, national origin, gender, religion, age, disability, political beliefs, sexual orientation, and marital or family status.

Author Contributions: JB, EAB designed research; JB, EAB, GM, AP, JAM, WWW, GL, RC performed research and analyzed the data; JB, EAB wrote the paper. All authors read and approved the final manuscript.

Conflicts of Interest: The authors declare no conflict of interest. 


\section{References}

1. Kimball, D.; Parish, M.E.; Braddock, R. Oranges and tangerines. In Processing Fruits: Science and Technology; Barrett, D.M., Somogyi, L.P., Ramaswamy, H.S., Eds.; CRC Press: Boca Raton, FL, USA, 2004; pp. 617-638.

2. Soule, J.; Grierson, W.; Blair, J. Quality tests for citrus fruits; University of Florida, Cooperative Extention Service: Gainesville, FL, USA, 1967; p. 315.

3. Ritenour, M.A. Orange. The Commercial Storage of Fruits, Vegetables, and Florist and Nursery Stocks; Agriculture Handbook, No. 66; Gross, K., Wang, C.Y., Saltveit, M., Eds.; U.S. Department of Agriculture: Washington, DC, USA, 2014. Available online: http://www.ba.ars.usda.gov/hb66/orange.pdf (accessed on 28 December 2015).

4. Chen, C. Models for seasonal changes in ${ }^{\circ}$ Brix and ratio of citrus fruit juice. Proc. Fla. State Hort. Soc. 1990, 103, 251-255.

5. Maier, V.; Hasegawa, S.; Bennett, R.; Echols, L. Limonin and limonoids: Chemistry, biochemistry, and juice bitterness. In Citrus Nutrition and Quality; Nagy, S., Attaway, J.A., Eds.; American Chemical Society: Washington, DC, USA, 1980; pp. 3-24.

6. Hasegawa, S.; Miyake, M. Biochemistry and biological functions of citrus limonoids. Food Rev. Int. 1996, 12, 413-435. [CrossRef]

7. Baldwin, E.; Bai, J.; Plotto, A.; Ritenour, M. Citrus fruit quality assessment: Producer and consumer perspectives. Stewart Postharvest Rev. 2014, 10, 1-7.

8. Dagulo, L.; Danyluk, M.D.; Spann, T.M.; Valim, M.F.; Goodrich-Schneider, R.; Sims, C.; Rouseff, R. Chemical characterization of orange juice from trees infected with citrus greening (Huanglongbing). J. Food Sci. 2010, 75, C199-C207. [CrossRef] [PubMed]

9. Perez-Cacho, P.R.; Rouseff, R.L. Fresh squeezed orange juice odor: A review. Critical Rev. Food Sci. Nutr. 2008, 48, 681-695. [CrossRef] [PubMed]

10. Plotto, A.; Margaría, C.A.; Goodner, K.L.; Baldwin, E.A. Odour and flavour thresholds for key aroma components in an orange juice matrix: Esters and miscellaneous compounds. Flavour Fragr. J. 2008, 23, 398-406. [CrossRef]

11. Plotto, A.; Margaría, C.A.; Goodner, K.L.; Goodrich, R.; Baldwin, E.A. Odour and flavour thresholds for key aroma components in an orange juice matrix: Terpenes and aldehydes. Flavour Fragr. J. 2004, 19, 491-498. [CrossRef]

12. Shaw, P.E. Fruit II. In Volatile Compounds in Foods and Beverages; Maarse, H., Ed.; Marcel Dekker, Inc.: New York, NY, USA, 1991; pp. 305-327.

13. González-Mas, M.C.; Rambla, J.L.; Alamar, M.C.; Gutiérrez, A.; Granell, A. Comparative analysis of the volatile fraction of fruit juice from different Citrus species. PLoS ONE 2011, 6, e22016. [CrossRef] [PubMed]

14. Cameron, R.G.; Baker, R.A.; Grohmann, K. Multiple forms of pectinmethylesterase from citrus peel and their effects on juice cloud stability. J. Food Sci. 1998, 63, 253-256. [CrossRef]

15. Brat, P.; Rega, B.; Alter, P.; Reynes, M.; Brillouet, J.M. Distribution of volatile compounds in the pulp, cloud, and serum of freshly squeezed orange juice. J. Agric. Food Chem. 2003, 51, 3442-3447. [CrossRef] [PubMed]

16. Radford, T.; Kawashima, K.; Friedel, P.K.; Pope, L.E.; Gianturco, M.A. Distribution of volatile compounds between the pulp and serum of some fruit juices. J. Agric. Food Chem. 1974, 22, 1066-1070. [CrossRef]

17. Gottwald, T.R. Current epidemiological understanding of citrus huanglongbing. Ann. Rev. Phytopathol. 2010, 48, 119-139. [CrossRef] [PubMed]

18. Baldwin, E.; Plotto, A.; Manthey, J.; McCollum, G.; Bai, J.; Irey, M.; Cameron, R.; Luzio, G. Effect of Liberibacter infection (Huanglongbing disease) of citrus on orange fruit physiology and fruit/fruit juice quality: Chemical and physical analyses. J. Agric. Food Chem. 2010, 58, 1247-1262. [CrossRef] [PubMed]

19. Plotto, A.; Baldwin, E.; McCollum, G.; Manthey, J.; Narciso, J.; Irey, M. Effect of Liberibacter infection (Huanglongbing or "Greening" disease) of citrus on orange juice flavor quality by sensory evaluation. J. Food Sci. 2010, 75, S220-S230. [CrossRef] [PubMed]

20. Li, W.; Hartung, J.S.; Levy, L. Quantitative real-time PCR for detection and identification of Candidatus Liberibacter species associated with citrus huanglongbing. J. Microbiol. Methods 2006, 66, 104-115. [PubMed]

21. Bai, J.; Baldwin, E.; Liao, H.L.; Zhao, W.; Kostenyuk, I.; Burns, J.; Irey, M. Extraction of DNA from orange juice, and detection of bacterium Candidatus Liberibacter asiaticus by real-time PCR. J. Agric. Food Chem. 2013, 61, 9339-9346. [CrossRef] [PubMed] 
22. Zhao, W.; Baldwin, E.A.; Bai, J.; Plotto, A.; Irey, M.S. Method for Assessing Juice/Cider Quality and/or Safety. U.S. Patent 20150093755 A1, 2 April 2015.

23. Baldwin, E.A.; Bai, J.; Plotto, A.; Cameron, R.; Luzio, G.; Narciso, J.; Manthey, J.; Widmer, W.; Ford, B.L. Effect of extraction method on quality of orange juice: Hand-squeezed, commercial-fresh squeezed and processed. J. Sci. Food Agric. 2012, 92, 2029-2042. [CrossRef] [PubMed]

24. Scott, W.C.; Veldhuis, M.K. Rapid estimation of recoverable oil in citrus juices by bromate titration. J. Assoc. Off. Anal. Chem. 1966, 49, 628-633.

25. Bai, J.; Manthey, J.A.; Ford, B.L.; Luzio, G.; Cameron, R.G.; Narciso, J.; Baldwin, E.A. Effect of extraction, pasteurization and cold storage on flavonoids and other secondary metabolites in fresh orange juice. J. Sci. Food Agric. 2013, 93, 2771-2781. [CrossRef] [PubMed]

26. Manthey, J.A. Differences in secondary metabolites in leaves from orange (Citrus sinensis L.) trees affected with greening disease (Huanglongbing) (HLB). Proc. Fla. State Hort. Soc. 2008, 121, 285-288.

27. Hasegawa, S.; Bennett, R.D.; Herman, Z.; Fong, C.H.; Ou, P. Limonoid glucosides in citrus. Phytochemistry 1989, 28, 1717-1720. [CrossRef]

28. Ohta, H.; Fong, C.H.; Berhow, M.; Hasegawa, S. Thin-layer and high-performance liquid chromatographic analyses of limonoids and limonoid glucosides in Citrus seeds. J. Chromatogr. A 1993, 639, 295-302. [CrossRef]

29. Bai, J.; Baldwin, E.; Stover, E.; Driggers, R.; Hearn, J. Volatile Profile Comparison of USDA Sweet Orange-Like Hybrids Versus "Hamlin" and "Ambersweet". Hort Sci. 2014. in press.

30. U.S. Department of Agriculture. United States Standards for Grades of Orange Juice; USDA-AMS: Washington, DC, USA, 1983; p. 15.

31. Rich, T.F. Orange stripper essence and stripper oil having high ratios of more desirable to less desirable flavor compounds. U.S. Patent No. 4,973,485, 27 November 1990.

32. Knight, T.G.; Klieber, A.; Sedgley, M. The relationship between oil gland and fruit development in Washington navel orange (Citrus sinensis (L.) Osbeck). Ann. Bot. 2001, 88, 1039-1047. [CrossRef]

33. Turner, G.W. A brief history of the lysigenous gland hypothesis. Bot. Re. 1999, 65, 76-88. [CrossRef]

34. Matthews, R.F. Frozen Concentrated Orange Juice from Florida Oranges; Univ. Fla. IFAS Extension: Gainsville, FL, USA, 1994; pp. 1-4.

35. Morse, R.L.D. Selected studies of consumer preferences for canned orange juices. Proc. Fla. State Hortic. Soc. 1952, 65, 230-234.

36. Baldwin, E.A. Citrus fruit. In Biochemistry of Fruit Ripening; Seymour, G.B., Taylor, J.E., Tucker, G.A., Eds.; Chapman and Hall: New York, NY, USA, 1993; pp. 107-149.

37. Echeverria, E.; Valich, J. Carbohydrate and enzyme distribution in protoplasts from valencia orange juice sacs. Phytochemistry 1988, 27, 73-76. [CrossRef]

38. Bruemmer, J.H. Terminal oxidase activity during ripening of Hamlin orange. Phytochemistry 1989, 28, 2901-2902. [CrossRef]

39. Guadagni, D.G.; Maier, V.P.; Turnbaugh, J.G. Effect of neodiosmin on threshold and bitterness of limonin in water and orange juice. J. Food Sci. 1976, 41, 681-684. [CrossRef]

40. Robertson, G.L.; Nisperos, M.O. Changes in the chemical constituents of New Zealand grapefruit during maturation. Food Chem. 1983, 11, 167-174. [CrossRef]

41. Kimball, D. Factors affecting the rate of maturation of citrus fruits. Proc. Fla. State Hort. Soc. 1984, 97, 40-44.

42. Dea, S.; Plotto, A.; Manthey, J.A.; Raithore, S.; Irey, M.; Baldwin, E. Interactions and thresholds of limonin and nomilin in bitterness perception in orange juice and other matrices. J. Sens. Stud. 2013, 28, 311-323. [CrossRef]

43. Drewnowski, A.; Gomez-Carneros, C. Bitter taste, phytonutrients, and the consumer: A review. Am. J. Clin. Nutr. 2000, 72, 1424-1435. [PubMed]

44. Rouseff, R. Bitterness in food products: An overview. In Bitterness in Foods and Beverages. Developments in Food Science; Rouoseff, R., Ed.; Elsevier: Amsterdam, The Netherlands, 1990; Volume 25, pp. 1-14.

45. Baker, R.A.; Cameron, R.G. Clouds of citrus juices and juice drinks. Food Technol. 1999, 53, 64-69.

46. Galant, A.L.; Widmer, W.W.; Luzio, G.A.; Cameron, R.G. Characterization of molecular structural changes in pectin during juice cloud destabilization in frozen concentrated orange juice. Food Hydrocoll. 2014, 41, 10-18. [CrossRef]

47. Thakur, B.R.; Singh, R.K.; Handa, A.K. Crit. Rev. Food Sci. Nutr. 1997, 37, 47. [PubMed] 
48. Sinclair, W.B.; Jolliffe, V.A. Pectic substances of Valencia oranges at different stages of maturity. J. Food Sci. 1961, 26, 125-130. [CrossRef]

49. Rouse, A.H.; Atkins, C.D.; Moore., E.L. The occurrence and evaluation of pectin in component parts of Valencia oranges during maturation. Proc. Fla. State Hort. Soc. 1962, 75, 307-311.

50. Rouse, A.; Moore, E. Effect of maturity, variety and processing on color, cloud, pectin and water-insoluble solids of orange juice. II. Pectin and water-insoluble solids. Proc. Fla. State Hort. Soc. 1975, 88, 342-345.

51. Cameron, R.G.; Baker, R.A.; Buslig, B.S.; Grohmann, K. Effect of juice extractor settings on juice cloud stability. J. Agric. Food Chem. 1999, 47, 2865-2868. [CrossRef] [PubMed]

52. Versteeg, C.; Rombouts, F.; Spaansen, C.; Pilnik, W. Thermostability and orange juice cloud destabilizing properties of multiple pectinesterases from orange. J. Food Sci. 1980, 45, 969-971. [CrossRef]

53. Sharon-Asa, L.; Shalit, M.; Frydman, A.; Bar, E.; Holland, D.; Or, E.; Lavi, U.; Lewinsohn, E.; Eyal, Y. Citrus fruit flavor and aroma biosynthesis: Isolation, functional characterization, and developmental regulation of Cstps1, a key gene in the production of the sesquiterpene aroma compound valencene. Plant J. 2003, 36, 664-674. [CrossRef] [PubMed]

54. Yu, Q.; Plotto, A.; Baldwin, E.A.; Bai, J.; Huang, M.; Yu, Y.; Dhaliwal, H.S.; Gmitter, F.G. Proteomic and metabolomic analyses provide insight into production of volatile and non-volatile flavor components in mandarin hybrid fruit. BMC Plant Biol. 2015, 15, 76. [CrossRef] [PubMed]

55. Bai, J.; Hagenmaier, R.D.; Baldwin, E.A. Volatile response of four apple varieties with different coatings during marketing at room temperature. J. Agric. Food Chem. 2002, 50, 7660-7668. [CrossRef] [PubMed]

56. Ueda, Y.; Tsuda, A.; Bai, J.; Fujishita, N.; Chachin, K. Characteristic pattern of aroma ester formation from banana, melon and strawberry with reference to the substrate specificity of ester synthetase and alcohol contents in pulp. J. Jpn. Food Sci. Technol. 1992, 39, 183-187. [CrossRef]

57. Frenkel, C.; Peters, J.S.; Tieman, D.M.; Tiznado, M.E.; Handa, A.K. Pectin methylesterase regulates methanol and ethanol accumulation in ripening tomato (Lycopersicon esculentum) fruit. J. Biol. Chem. 1998, 273, 4293-4295. [CrossRef] [PubMed]

58. Beekwilder, J.; Alvarez-Huerta, M.; Neef, E.; Verstappen, F.W.A.; Bouwmeester, H.J.; Aharoni, A. Functional Characterization of Enzymes Forming Volatile Esters from Strawberry and Banana. Plant Physiol. 2004, 135, 1865-1878. [CrossRef] [PubMed]

59. Matsui, K. Green leaf volatiles: Hydroperoxide lyase pathway of oxylipin metabolism. Curr. Opin. Plant Biol. 2006, 9, 274-280. [CrossRef] [PubMed]

60. Bai, J.; Baldwin, E.A.; Imahori, Y.; Kostenyuk, I.; Burns, J.; Brecht, J.K. Chilling and heating may regulate C6 volatile aroma production by different mechanisms in tomato (Solanum lycopersicum) fruit. Postharvest Biol. Technol. 2011, 60, 111-120. [CrossRef]

61. Wang, L.; Baldwin, E.A.; Plotto, A.; Luo, W.; Raithore, S.; Yu, Z.; Bai, J. Effect of methyl salicylate and methyl jasmonate pre-treatment on the volatile profile in tomato fruit subjected to chilling temperature. Postharvest Biol. Technol. 2015, 108, 28-38. [CrossRef]

62. Wyllie, S.G.; Leach, D.; Nonhebel, H.; Lusunzi, I. Biochemical pathways for the formation of esters in ripening fruit. In Flavour Science. Recent Developments; Taylor, A.J., Mottram, D.S., Eds.; Royal Society of Chemistry: Cambridge, UK, 1997; pp. 52-57.

63. Beltrán, G.; Bejaoui, M.A.; Jimenez, A.; Sanchez-Ortiz, A. Ethanol in olive Fruit. Changes during ripening. J. Agric. Food Chem. 2015, 63, 5309-5312. [CrossRef] [PubMed]

64. Rodríguez-Concepción, M. Boronat, A. Elucidation of the methylerythritol phosphate pathway for isoprenoid biosynthesis in bacteria and plastids. A metabolic milestone achieved through genomics. Plant Physiol. 2002, 130, 1079-1089. [CrossRef] [PubMed]

65. Kealey, K.; Kinsella, J.; Nagy, S. Orange juice quality with an emphasis on flavor components. Crit. Rev. Food Sci. Nutr. 1979, 11, 1-40. [CrossRef]

66. Alférez, F.; Burns, J.K. Postharvest peel pitting at non-chilling temperatures in grapefruit is promoted by changes from low to high relative humidity during storage. Postharvest Biol. Technol. 2004, 32, $79-87$. [CrossRef]

67. Qiao, Y.; Xie, B.J.; Zhang, Y.; Zhang, Y.; Fan, G.; Yao, X.L.; Pan, S.Y. Characterization of aroma active compounds in fruit juice and peel oil of Jinchen sweet orange fruit (Citrus sinensis (L.) Osbeck) by GC-MS and GC-O. Molecules 2008, 13, 1333-1344. [CrossRef] [PubMed] 
68. Ahmed, E.M.; Dennison, R.A.; Dougherty, R.H.; Shaw, P.E. Flavor and odor thresholds in water of selected orange juice components. J. Agric. Food Chem. 1978, 26, 187-191. [CrossRef]

69. Miyazaki, T.; Plotto, A.; Baldwin, E.A.; Reyes-De-Corcuera, J.I.; Gmitter, F.G., Jr. Aroma characterization of tangerine hybrids by gas-chromatography-olfactometry and sensory evaluation. J. Sci. Food Agric. 2012, 92, 727-735. [CrossRef] [PubMed]

70. Arctander, S. Perfume and Flavor Chemicals (Aroma Chemicals); Vol. I; Published by the Author: Montclair, NJ, USA, 1969; p. 332.

71. Ruiz Perez-Cacho, P.; Mahattanatawee, K.; Smoot, J.M.; Rouseff, R. Identification of sulfur volatiles in canned orange juices lacking orange flavor. J. Agric. Food Chem. 2007, 55, 5761-5767. [CrossRef] [PubMed]

72. Hausch, B.J.; Lorjaroenphon, Y.; Cadwallader, K.R. Flavor chemistry of lemon-lime carbonated beverages. J. Agric. Food Chem. 2015, 63, 112-119. [CrossRef] [PubMed]

73. Bazemore, R.; Rouseff, R.; Naim, M. Linalool in orange juice: Origin and thermal stability. J. Agric. Food Chem. 2003, 51, 196-199. [CrossRef] [PubMed]

74. Nisperos-Carriedo, M.O.; Shaw, P.E. Comparison of volatile flavor components in fresh and processed orange juices. J. Agric. Food Chem. 1990, 38, 1048-1052. [CrossRef]

75. Haleva-Toledo, E.; Naim, M.; Zehavi, U.; Rouseff, R. Formation of $\alpha$-terpineol in Citrus Juices, Model and Buffer Solutions. J. Food Sci. 1999, 64, 838-841. [CrossRef]

76. Moshonas, M.G.; Shaw, P.E. Isolation of trans, trans-2,4-decadienal and intermedeol from cold-pressed citrus oils. J. Agric. Food Chem. 1979, 27, 210-211. [CrossRef]

77. Selli, S.; Cabaroglu, T.; Canbas, A. Volatile flavour components of orange juice obtained from the cv. Kozan of Turkey. J. Food Compos. Anal. 2004, 17, 789-796. [CrossRef]

78. Baldwin, E.A.; Goodner, K.; Plotto, A. Interaction of volatiles, sugars, and acids on perception of tomato aroma and flavor descriptors. J. Food Sci. 2008, 73, S294-S307. [PubMed]

(C) 2016 by the authors; licensee MDPI, Basel, Switzerland. This article is an open access article distributed under the terms and conditions of the Creative Commons by Attribution (CC-BY) license (http://creativecommons.org/licenses/by/4.0/). 